BMJ Open

Diabetes

Research

\& Care

\title{
Prevalence, incidence and predictors of cardiovascular risk factors: longitudinal data from rural and urban South India and comparison with global data
}

\author{
Senthil K Vasan (1) , , ${ }^{1,2}$ Belavendra Antonisamy, ${ }^{3}$ Mahasampath Gowri, ${ }^{3}$ \\ Hepsy Y Selliah, ${ }^{3}$ Finney S Geethanjali, ${ }^{4}$ Felix S Jebasingh, ${ }^{5}$ Thomas V Paul, ${ }^{5}$ \\ Nihal Thomas, ${ }^{5}$ Fredrik Karpe (D) , ${ }^{1}$ Matthew Johnson (D) , ${ }^{2}$ Clive Osmond, ${ }^{2}$ \\ Caroline H D Fall ${ }^{2}$
}

To cite: Vasan SK, Antonisamy B, Gowri M, et al. Prevalence, incidence and predictors of cardiovascular risk factors: Iongitudinal data from rural and urban South India and comparison with global data. BMJ Open Diab Res Care 2020;8:e001782. doi:10.1136/ bmjdrc-2020-001782

- Supplemental material is published online only. To view, please visit the journal online (http://dx.doi.org/10.1136/ bmjdrc-2020-001782).

SKV and BA contributed equally.

Received 18 July 2020

Revised 12 September 2020 Accepted 15 September 2020

Check for updates

\section{(c) Author(s) (or their} employer(s)) 2020. Re-use permitted under CC BY. Published by BMJ.

For numbered affiliations see end of article.

Correspondence to Dr Senthil K Vasan; senthil.vasan@ocdem.ox.ac.uk

\section{ABSTRACT}

Introduction India has high mortality rates from cardiovascular disease (CVD). Understanding the trends and identifying modifiable determinants of CVD risk factors will guide preventive strategies and policy making. Research design and methods CVD risk factors (obesity, central obesity, and type 2 diabetes (T2D), hypertension, hypercholesterolemia and hypertriglyceridemia) prevalence and incidence were estimated in 962 (male 519) non-migrant adults from Vellore, South India, studied in: (1) 1998-2002 (mean age 28.2 years) and (2) 2013-2014 (mean age 41.7 years). Prevalence was compared with the Non-Communicable Disease Risk Collaboration (global) data. Incidence was compared with another Indian cohort from New Delhi Birth Cohort (NDBC). Regression analysis was used to test baseline predictors of incident CVD risk factors.

Results The prevalence at 28 and 42 years was $17 \%(95 \% \mathrm{Cl}$ $14 \%$ to $19 \%$ ) and $51 \%$ (95\% Cl $48 \%$ to $55 \%$ ) for overweight/ obesity, $19 \%$ (95\% Cl 17\% to 22\%) and 59\% (95\% Cl 56\% to $62 \%)$ for central obesity, $3 \%(95 \% \mathrm{Cl} 2 \%$ to $4 \%)$ and $16 \%(95 \% \mathrm{Cl} 14 \%$ to $19 \%$ ) for T2D, $2 \%$ (95\% Cl 1\% to $3 \%$ ) and $19 \%(95 \% \mathrm{Cl} 17 \%$ to $22 \%)$ for hypertension and $15 \%$ (95\% Cl $13 \%$ to $18 \%$ ) and $30 \%$ (95\% Cl $27 \%$ to $33 \%$ ) for hypertriglyceridemia. The prevalence of $\mathrm{T} 2 \mathrm{D}$ at baseline and follow-up and hypertension at follow-up was comparable with or exceeded that in high-income countries despite lower obesity rates. The incidence of most risk factors was lower in Vellore than in the NDBC. Waist circumference strongly predicted incident $\mathrm{T2D}$, hypertension and hypertriglyceridemia. Conclusions A high prevalence of CVD risk factors was evident at a young age among Indians compared with high and upper middle income countries, with rural rates catching up with urban estimates. Adiposity predicted higher incident CVD risk, but the prevalence of hypertension and T2D was higher given a relatively low obesity prevalence. Preventive efforts should target both rural and urban India and should start young.

\section{INTRODUCTION}

Asian Indians aged 35-64 years lost an estimated 9.2 million years of potentially productive life due to cardiovascular disease (CVD) in 2000, a figure expected to rise to 17.9 million years by $2030 .^{1}$ The

\section{Significance of this study}

What is already known about this subject?

- Cardiovascular disease (CVD) risk burden is increasing in low-income and middle-income countries and contributes significantly to the overall morbidity and mortality.

- Nationwide data from India demonstrate heterogeneity in the prevalence of CVD risk factors within the country; there is very little incidence data.

What are the new findings?

- The prevalence of CVD risk factors in India is comparable with or exceeds that in high-income countries like USA and Europe, even though obesity levels are lower.

- Adiposity at baseline, particularly waist circumference, is a strong predictor of incident risk factors.

- The prevalence of CVD risk factors is higher in rural than urban communities, but the incidence is comparable or higher in the rural setting indicating that the rural population is catching up.

How might these results change the focus of research or clinical practice?

- Strategies to prevent CVD should be strengthened in both rural and urban India to minimize health inequalities and should start young.

Global Burden of Disease (GBD) study reported the age-standardized CVD death rate in India as 282 per 100000 population in 2017 , accounting for $24 \%$ of total deaths, which is higher than the global average (233 per 100000 ) and high-income countries (HICs) like the USA ( 151 per 100 $000)$ and UK (122 per 100000$).^{2}$

GVD-related mortality in India increased by $34 \%$ from 1990 to $2016 .{ }^{3}$ Nationwide representative data on the prevalence of CVD risk factors are available ${ }^{4-6}$ and the 
India State-Level Disease Burden Initiative (part of the GBD study) has recently reported age-standardized prevalence data and trends for diabetes, hypertension and obesity according to the economic transition levels of different Indian states ${ }^{7}$ and provides useful information on the disease burden. There remains, however, a lack of longitudinal studies examining changes in CVD risk factors over time in the same population. Such incidence data, and predictors of incidence, are critical to understanding risk factor dynamics within a population and to evaluate the effectiveness of preventive interventions.

In the current study, we used longitudinal data from the Vellore Birth Cohort (VBC) in South India to report trends in the prevalence, incidence and predictors of key CVD risk factors in a stable, non-migrant rural and urban population followed over 13.6 years from age 28 years in 1998-2002 (baseline) to 42 years in 2013-2014. We compared the prevalence at baseline and follow-up with global rates using data from the Non-Communicable Disease Risk Collaboration (NCD-RisC) and compared incidence with another Indian study (the urban New Delhi Birth Cohort (NDBC) study). We also examined 28-year adiposity, rural/urban residence and lifestyle factors as predictors of incident risk factors at 42 years.

\section{RESEARCH DESIGN AND METHODS}

\section{Study population}

Vellore is situated $135 \mathrm{~km}$ from Chennai, the state capital of Tamil Nadu, and has a current population of $\sim 484690$ individuals. The VBC includes men and women born in 1969-1973 to population-based samples of pregnant women recruited from Vellore town (urban) and adjoining rural villages. Details of the cohort are provided elsewhere. ${ }^{8}$ In brief, singleton newborns $(n=10670)$ born to mothers in 1969-1973, from defined areas of Vellore town and 26 nearby rural villages were followed through birth (phase $1, \mathrm{n}=10670$ ), infancy (phase 2, age 0-3 months, $\mathrm{n}=5753$ ), childhood (phase 3 , age $6-8$ years, $\mathrm{n}=5541$ ) and adolescence (phase 4 , age $10-15$ years, $\mathrm{n}=2672$ ). The adult follow-up included two phases: phase 5 $(1998-2002$, mean age 28 years, $n=2181)$ and phase 6 (2013-2014, mean age 42 years, $\mathrm{n}=1080$ ). The current analysis includes 962 individuals (rural 457; urban 505) seen at both adult follow-ups. Participants who migrated between phases 5 and 6 , either rural-urban $(n=36)$ or urban-rural $(n=82)$ were excluded to avoid any confounding effect of migration.

\section{Demographic and lifestyle measurements}

Data were collected using the same methods at age 28 and 42 years. Educational status, tobacco and alcohol use, physical activity (PA) and socioeconomic status (SES) were collected by trained field workers using standardized questionnaires. Attained education was recorded at seven levels from 'no schooling' (level 1: 0 years), primary school (level 2: 1-8 years), middle school (level 3: 9-15 years), high school certificate (level 4: 9-12 years), high school (level 5: >12 years), other graduate (level 6) and professional degree (level 7). Tobacco use was categorized as non-smoker, mild, moderate or heavy smokers and included tobacco chewing and snuff, as well as smoking (indigenous beedi's and/cigarettes). These were converted into cigarette/beedi equivalents per day and categorized as 0: none, 1-: mild, ${ }^{9}$ 2: moderate $^{9-19}$ and 3: heavy $(>20)$. The frequencies and quantity of consumption of beer, wine, and spirits were converted into units of alcohol per week ( 1 unit $=574 \mathrm{~mL}$ beer or $125 \mathrm{~mL}$ wine or $23 \mathrm{~mL}$ spirits $)$. They were categorized as $0=$ none $(0$ units), $1=$ mild ( $\leq 7$ units), $2=$ moderate (8-21 units) and $3=$ heavy ( $>21$ units) or dichotomized into current consumers or non-consumers of alcohol. A possessions score was used to define SES, based on ownership of five household items (electric fan, bicycle, car/ jeep, motor bike and television), which was recorded at both time points. PA score was calculated as previously described. ${ }^{8}$

\section{Anthropometric and biochemical measurements}

During both adult phases, anthropometry (height, weight and waist circumference (WC)) was measured using standardized protocols. Blood pressure (BP) was recorded seated using a digital sphygmo-manometer (Omron M3 Corporation, Tokyo, Japan) after $5 \mathrm{~min}$ seated. Fasting glucose and lipids and 2-hour blood glucose was measured following a $75 \mathrm{~g}$ oral glucose tolerance test (OGTT). Glucose was measured on a Roche Cobas 800 Autoanalyser (hexokinase-mediated reaction) excluding participants with known diabetes and lipids by standard enzymatic methods. All participants provided informed consent.

\section{Endpoints}

Continuous variables included anthropometry, systolic and diastolic BP and biochemical markers. Binary endpoints were defined using WHO criteria for overweight (body mass index $(\mathrm{BMI}) \geq 25 \mathrm{~kg} / \mathrm{m}^{2}$ ), obesity (BMI $\geq 30 \mathrm{~kg} / \mathrm{m}^{2}$ ), central obesity (men: WC $\geq 90 \mathrm{~cm}$, women: $\geq 80 \mathrm{~cm}$ ), impaired fasting glucose (IFG ; fasting glucose $\geq 6.1 \mathrm{mmol} / \mathrm{L}$ and $<7.0 \mathrm{mmol} / \mathrm{L}$ ), impaired glucose tolerance (IGT; fasting glucose $<7.0 \mathrm{mmol} / \mathrm{L}$ and 2-hour glucose $\geq 7.8$ and $<11.1 \mathrm{mmol} / \mathrm{L}$ ), type 2 diabetes (T2D; fasting glucose $\geq 7.0 \mathrm{mmol} / \mathrm{L}$ or 2 -hour glucose $\geq 11.1 \mathrm{mmol} / \mathrm{L}$ or on antidiabetic medication) and hypertension (systolic $\mathrm{BP} \geq 140 \mathrm{~mm} \mathrm{Hg}$ or diastolic BP (DBP) $\geq 90 \mathrm{~mm} \mathrm{Hg}$, or on antihypertensives). National Cholesterol Education Program guidelines were used to define hypertriglyceridemia (serum triglycerides $\geq 1.5 \mathrm{mmol} / \mathrm{L}$ or on lipid-lowering medication), hypercholesterolemia (serum total cholesterol $\geq 5.2 \mathrm{mmol} / \mathrm{L}$ or on medication) and low HDL-cholesterol (HDL-cholesterol 
Table 1 Prevalence of CVD risk factors at phase 5 (baseline) and phase 6 (follow-up) in the Vellore Birth Cohort according to sex and place of residence (rural or urban)

\begin{tabular}{|c|c|c|c|c|c|}
\hline \multirow[b]{2}{*}{ CVD risk factor } & \multirow[b]{2}{*}{ Phase } & \multicolumn{2}{|l|}{ Men } & \multicolumn{2}{|l|}{ Women } \\
\hline & & $\begin{array}{l}\text { Rural }(n=240) \\
\%(95 \% \mathrm{Cl})\end{array}$ & $\begin{array}{l}\text { Urban }(n=279) \\
\%(95 \% \mathrm{Cl})\end{array}$ & $\begin{array}{l}\text { Rural }(n=217) \\
\%(95 \% \mathrm{Cl})\end{array}$ & $\begin{array}{l}\text { Urban }(n=226) \\
\%(95 \% \mathrm{Cl})\end{array}$ \\
\hline \multirow{3}{*}{$\begin{array}{l}\text { Overweight/obese, } \\
\text { n (\%) }\end{array}$} & Phase 5 & 6.7 (3.5 to 9.8$)$ & 18.9 (14.4 to 23.6$)$ & $9.2(5.4$ to 13.1$)$ & 31.9 (25.8 to 37.9$)$ \\
\hline & Phase 6 & 35.4 (29.4 to 41.5$)$ & 50.5 (44.7 to 56.4$)$ & 49.8 (43.1 to 56.4 ) & 70.8 (64.9 to 76.7$)$ \\
\hline & $\begin{array}{l}\text { Change in } \\
\text { percentage }\end{array}$ & +28.8 (21.9 to 35.6$)$ & $+31.6(24.1$ to 56.4$)$ & +40.6 (32.9 to 48.2$)$ & $+38.9(30.5$ to 47.4$)$ \\
\hline \multirow[t]{3}{*}{ Obesity, n (\%) } & Phase 5 & $0.8(-0.03$ to 2.0$)$ & 2.2 (0.4 to 3.9$)$ & $0.5(-0.4$ to 1.4$)$ & 8.0 (4.4 to 11.5$)$ \\
\hline & Phase 6 & 5.4 (2.6 to 8.3$)$ & 13.6 (9.6 to 17.6$)$ & 15.7 (10.8 to 20.5$)$ & 34.1 (27.9 to 40.2 ) \\
\hline & $\begin{array}{l}\text { Change in } \\
\text { percentage }\end{array}$ & $+4.6(1.5$ to 7.7$)$ & $+11.4(7.1$ to 15.8$)$ & +15.2 (10.3 to 20.1$)$ & +26.1 (19.0 to 33.2$)$ \\
\hline \multirow{3}{*}{$\begin{array}{l}\text { Central obesity, } \\
\mathrm{n}(\%)\end{array}$} & Phase 5 & 8.8 (5.2 to 12.3$)$ & 20.8 (16.0 to 25.6$)$ & 13.8 (9.2 to 18.4$)$ & 35.0 (28.7 to 41.2$)$ \\
\hline & Phase 6 & 43.8 (37.5 to 50.0$)$ & $61.3(55.6$ to 67.0$)$ & 54.8 (48.2 to 61.5$)$ & 76.6 (71.0 to 82.1$)$ \\
\hline & $\begin{array}{l}\text { Change in } \\
\text { percentage }\end{array}$ & +35.0 (27.8 to 42.2$)$ & +40.55 (33.1 to 47.9$)$ & +41.0 (33.0 to 49.1$)$ & +41.6 (33.3 to 49.9$)$ \\
\hline \multirow{3}{*}{$\begin{array}{l}\text { Impaired fasting } \\
\text { glucose/impaired } \\
\text { glucose tolerance, } \\
\text { n (\%) }\end{array}$} & Phase 5 & 20.8 (15.7 to 26.0 ) & 19.0 (14.4 to 23.6$)$ & 22.1 (16.6 to 27.6 ) & 27.0 (21.2 to 32.8$)$ \\
\hline & Phase 6 & 11.7 (7.6 to 15.7$)$ & 14.7 (10.5 to 18.8$)$ & 15.2 (10.4 to 20.0$)$ & 22.6 (17.1 to 28.0 ) \\
\hline & $\begin{array}{l}\text { Change in } \\
\text { percentage }\end{array}$ & $-9.1(-15.7$ to 2.6$)$ & $-4.3(-10.5$ to 1.9$)$ & $-6.9(-14.2$ to 0.4$)$ & $-4.4(-12.4$ to 3.5$)$ \\
\hline \multirow{3}{*}{$\begin{array}{l}\text { Type } 2 \text { diabetes, } \\
\text { n (\%) }\end{array}$} & Phase 5 & 1.7 (0.0 to 3.3$)$ & 3.9 (1.7 to 6.2$)$ & 1.8 (0.1 to 3.6$)$ & 3.5 (1.1 to 5.9$)$ \\
\hline & Phase 6 & 18.8 (13.8 to 23.7$)$ & 17.9 (13.4 to 22.4$)$ & 11.5 (7.3 to 15.8$)$ & 16.8 (11.9 to 21.7$)$ \\
\hline & $\begin{array}{l}\text { Change in } \\
\text { percentage }\end{array}$ & +17.1 (11.9 to 22.3$)$ & +14.0 (8.9 to 19.0$)$ & +9.7 (5.1 to 14.3$)$ & $+13.3(7.8$ to 18.7$)$ \\
\hline \multirow{3}{*}{$\begin{array}{l}\text { Hypertension, } \\
\text { n (\%) }\end{array}$} & Phase 5 & 1.7 (0.0 to 3.3$)$ & 5.4 (2.7 to 8.0$)$ & $0.5(-0.4$ to 1.4$)$ & 0.9 (-0.3 to 2.1$)$ \\
\hline & Phase 6 & 24.2 (18.8 to 29.6 ) & 28.4 (23.0 to 33.6 ) & $10.6(6.5$ to 14.7$)$ & $12.4(8.1$ to 16.7$)$ \\
\hline & $\begin{array}{l}\text { Change in } \\
\text { percentage }\end{array}$ & +22.5 (16.8 to 28.2$)$ & $+23.0(17.0$ to 28.9$)$ & +10.1 (5.9 to 14.3$)$ & +11.5 (7.0 to 16.0$)$ \\
\hline \multirow{3}{*}{$\begin{array}{l}\text { Hypertriglyceridemia, } \\
\text { n (\%) }\end{array}$} & Phase 5 & 16.7 (12.0 to 21.4$)$ & 25.5 (20.3 to 30.6$)$ & 6.5 (3.2 to 9.7$)$ & 10.6 (6.6 to 14.6$)$ \\
\hline & Phase 6 & 38.8 (32.6 to 44.9 ) & 42.7 (36.8 to 48.5 ) & 17.1 (12.0 to 22.1$)$ & 16.8 (11.9 to 21.7$)$ \\
\hline & $\begin{array}{l}\text { Change in } \\
\text { percentage }\end{array}$ & +22.1 (14.3 to 29.8$)$ & +17.2 (9.5 to 24.9$)$ & +10.6 (4.6 to 16.6$)$ & $+6.2(-0.1$ to 12.5$)$ \\
\hline \multirow{3}{*}{$\begin{array}{l}\text { Hypercholesterolemia, } \\
\text { n (\%) }\end{array}$} & Phase 5 & 4.2 (1.6 to 6.7$)$ & 15.4 (11.2 to 19.6$)$ & 4.2 (1.5 to 6.8$)$ & 12.8 (8.5 to 17.2$)$ \\
\hline & Phase 6 & 15.8 (11.2 to 20.5$)$ & $\begin{array}{l}27.2 \\
\text { (22.0 to } 32.5)\end{array}$ & 8.8 (5.0 to 12.5$)$ & 18.6 (13.5 to 23.7$)$ \\
\hline & $\begin{array}{l}\text { Change in } \\
\text { percentage }\end{array}$ & $+11.6(6.4$ to 16.9$)$ & +11.8 (5.1 to 18.6$)$ & +4.6 (0.0 to 9.2$)$ & $+5.8(-0.9$ to 12.4$)$ \\
\hline \multirow{3}{*}{$\begin{array}{l}\text { Low HDL-cholesterol, } \\
\mathrm{n}(\%)\end{array}$} & Phase 5 & 65.8 (59.8 to 71.8$)$ & 61.3 (55.6 to 67.0 ) & 82.0 (76.9 to 87.1$)$ & 80.1 (74.9 to 85.3$)$ \\
\hline & Phase 6 & 45.8 (39.5 to 52.1$)$ & 54.8 (49.0 to 60.7$)$ & 74.7 (68.9 to 80.4$)$ & 69.5 (63.5 to 75.5$)$ \\
\hline & $\begin{array}{l}\text { Change in } \\
\text { percentage }\end{array}$ & $-20.0(-28.7$ to -11.3$)$ & $-6.5(-14.6$ to 1.7$)$ & $-7.3(-15.1$ to 0.3$)$ & $-10.6(-18.6$ to -2.7$)$ \\
\hline
\end{tabular}

CVD, cardiovascular disease; HDL, high-density lipoprotein.

men: $<1.03 \mathrm{mmol} / \mathrm{L}$; women: $<1.29 \mathrm{mmol} / \mathrm{L}$ or on medication). Incident cases of these binary endpoints were defined as new cases diagnosed at phase 6 and absent at phase 5 .

\section{Statistical analysis}

Kernel density plots were used to show changes in continuous risk factors between baseline and follow-up. The prevalence of binary endpoints was calculated as the ratio of the total number of cases to the study population at each age and presented as number (percentage). For global comparisons, we acquired age-specific and year-specific prevalence data (cases per 1000) for obesity, ${ }^{20}$ diabetes $^{9}$ and hypertension ${ }^{10}$ from NCD-RisC collaborators for the 21 most populous countries globally. The VBC prevalence was compared with NCD-RisC for the most closely matched age ranges (25-29 years and 40-44 years) and years (2000 and 2013). The incidence in VBC (the proportion of new cases per at-risk sample per year) was compared with a north Indian cohort 

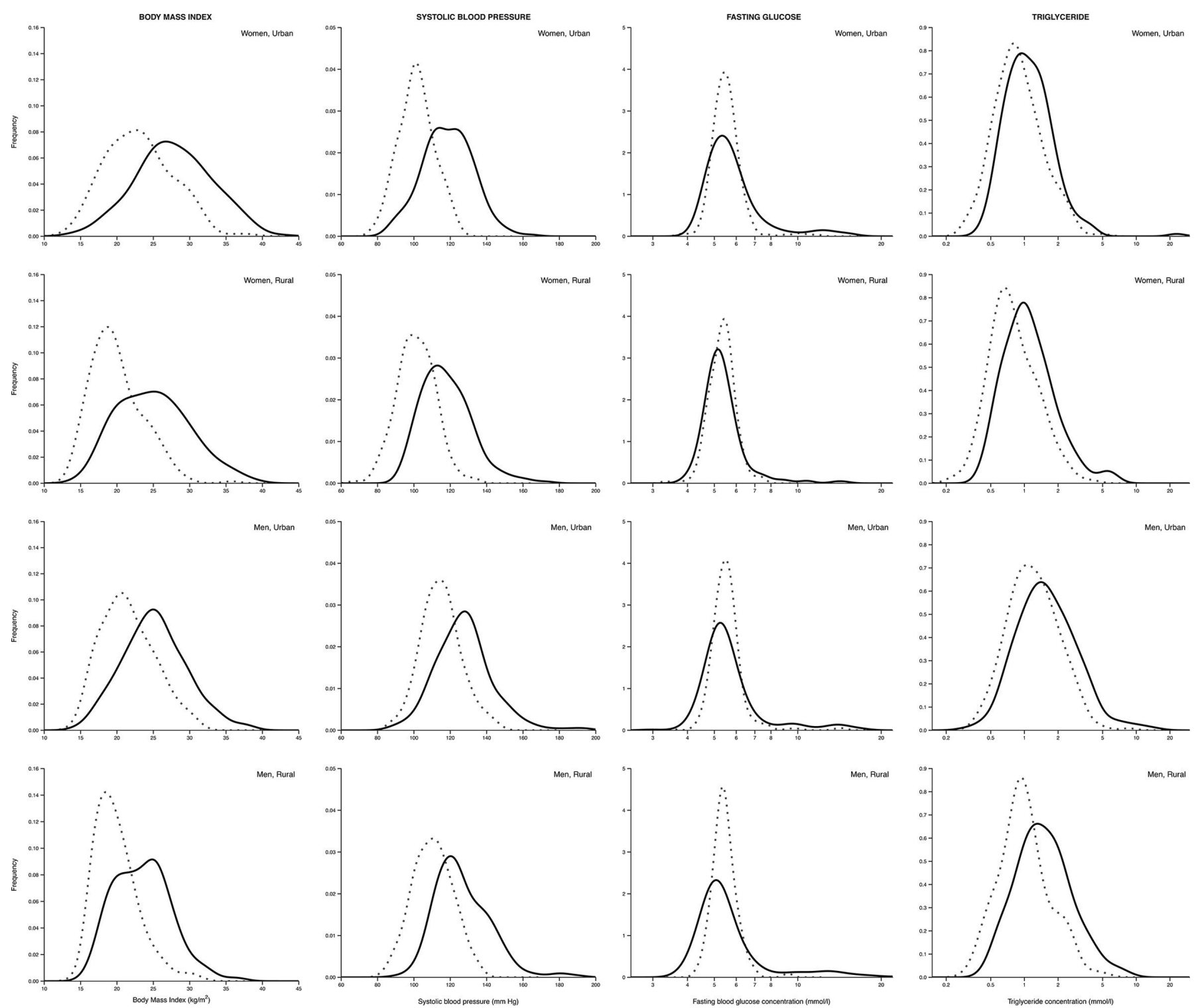

Figure 1 Kernel density plots showing the change in body mass index, systolic blood pressure, fasting glucose and serum triglycerides from phase 5 to phase 6 in rural and urban men and women. Dotted lines represent phase 5 and solid lines represent phase 6 .

(NDBC) of similar age in which similar CVD risk measurements were made during 1998-2002 and 2006-2009. ${ }^{11}$ Logistic regression was used to identify predictors of incident hypertension, T2D and hypertriglyceridemia, adjusted for age, sex, rural/urban residence, alcohol and tobacco use, SES, education level, family history and PA. We have previously reported the representativeness of cohort members who were followed-up to phase 5 compared with the remainder of the original birth cohort and showed only small differences in early growth. ${ }^{12}$ In a sensitivity analysis, we assessed the representativeness of the analysis sample by comparing sociodemographic, anthropometric and risk marker data at phase 5 in those studied and not studied in phase 6 , using t-tests and $\chi^{2}$ tests.

\section{RESULTS}

The demographic, anthropometric and cardiovascular risk factors of the 962 individuals in phase 5 and phase 6 are presented in the online supplemental table 1 . Tobacco use decreased among rural men but remained stable in urban men. Alcohol consumption increased in rural men. Tobacco and alcohol consumption remained non-existent among women in both phases. SES increased and PA decreased in all groups.

\section{Prevalence of CVD risk factors}

A consistent increase in the prevalence of binary CVD outcomes was seen (table 1). Exceptions were IFG/IGT, the prevalence of which decreased, counter-balanced by an increase in T2D, and low HDL-cholesterol. Urban residents had a higher prevalence of these outcomes than rural residents at both time points. However, the increase 


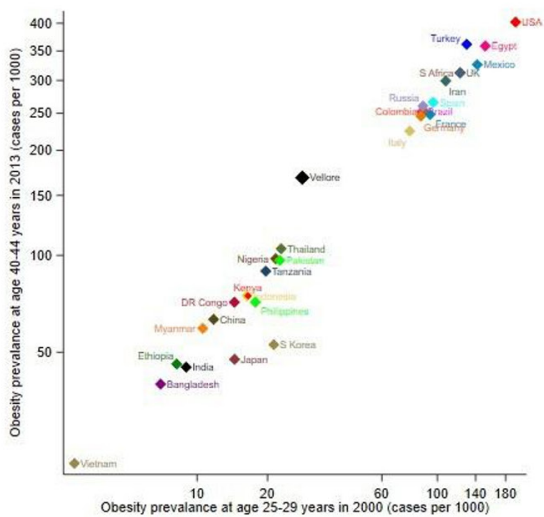

A

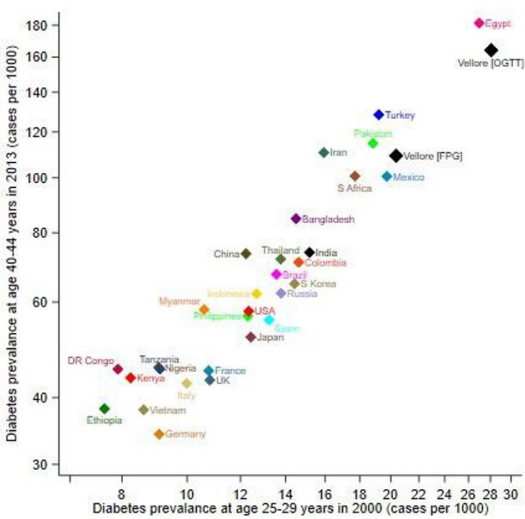

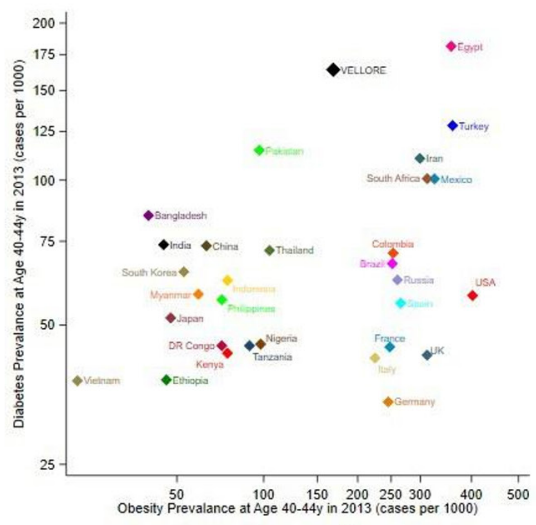

c

Figure 2 Prevalence (cases per 1000 persons) of obesity, diabetes and diabetes (y-axis), in relation to the prevalence of obesity (x-axis) at age 40-44 years in 2013 in Vellore compared with global NCD-RisC data for the 21 most populous countries at age 25-29 years measured in 2000. OGTT refers to the prevalence estimate based on oral glucose tolerance test criteria (fasting glucose $\geq 7.0 \mathrm{mmol} / \mathrm{L}$ or 2 -hour OGTT $\geq 11.1 \mathrm{mmol} / \mathrm{L}$ ) and FPG refers to the prevalence estimate based on fasting plasma glucose only (fasting glucose $\geq 7.0 \mathrm{mmol} / \mathrm{L}$ ) in Vellore. NCD-RisC, Non-Communicable Disease Risk Collaboration.

was comparable in both groups (change in percentage, table 1). The highest change was noticed with central obesity. A corresponding increase in mean BMI, WC, $\mathrm{BP}$, glucose and lipid concentrations was observed from phase 5 to phase 6 (online supplemental table 1) with a right shift in distribution (figure 1 and online supplemental figure 1) for most of the cardiovascular risk factors except fasting glucose.

\section{Comparison of prevalence in Vellore with NCD-RisC (global)} data

Figure 2 shows data from NCD-RisC for the prevalence of obesity, T2D and hypertension in 21 countries, with the estimates from Vellore added for comparison.

For obesity (figure 2A), the countries form two clusters, with a high obesity prevalence at both age/time points in HICs (USA and Europe) and upper middle-income countries (UMICs) (Turkey, Mexico, South Africa, Iran and Brazil), and low obesity prevalence in low-income countries and low-income and middle-income countries (LMICs; Vietnam, Bangladesh and Ethiopia). The NCD-RisC estimate for India (an LMIC) falls in the latter group. Exceptions to this pattern are Egypt (an LMIC with high obesity rates) and Japan and South Korea (HICs with low obesity rates). The Vellore estimate is between the two main clusters at both age/timepoints, indicating an obesity prevalence above other LMICs and below UMICs and HICs.

For diabetes (figure 2B), values at both age/time points are again correlated, but the ranking of countries differs markedly from that for obesity. HICs (USA and Europe) have a low diabetes prevalence despite high obesity rates. The MICs with comparably high obesity prevalence (Iran, Mexico, Turkey, South Africa and Egypt) have a higher diabetes prevalence than the HICs. Bangladesh, India and Pakistan stand out as countries with low obesity rates but a high diabetes prevalence. Egypt and Vellore stand out with the highest prevalence. The Vellore prevalence is even higher than the NCD-RisC estimate for India and remains strikingly high even when fasting glucose is used to define diabetes, rather than the complete glucose data.

For hypertension (figure 2C), HICs again had the lowest prevalence and LMICs the highest, with Pakistan and several African countries the leaders. The prevalence doubled in all countries between the two age/time-points. The hypertension prevalence in Vellore at baseline is markedly lower than NCDRisC estimates for all other countries. At follow-up, however, the prevalence is comparable with the NCDRisC data for India as a whole and/or other MICs.

\section{Incidence of CVD risk factors}

The highest risk factor incidence was observed for central obesity (table 2). The incidence of low HDLcholesterol was also high in women. The incidence of obesity markers was higher in the urban than the rural population, but the incidence of other risk factors was similar in both groups. The incidence of all risk factors was 1.5-3 times higher in the NDBC compared with the VBC, except that of T2D and low HDL-cholesterol, which was similar in both cohorts.

\section{Predictors of incident hypertension, T2D and hypertriglyceridemia}

Higher 28-year WG was strong independent predictor of incident T2D, hypertension and hypertriglyceridemia (table 3). Other significant predictors were: (for hypertension) male sex, higher SES, a family history of hypertension and rural residence; (for T2D) rural residence; and (for hypertriglyceridemia) male sex and alcohol and tobacco use.

\section{Sensitivity analysis}

For rural women, there were no significant differences in phase 5 variables between those studied and notstudied in phase 6 (online supplemental tables 2 and 3). Among rural men, there was a small difference in height 
Table 2 Annual incidence rate per 100 persons $(95 \% \mathrm{Cl})$ of CVD risk factors during follow-up according to sex and place of residence in Vellore and in New Delhi

\begin{tabular}{|c|c|c|c|c|c|}
\hline \multirow[b]{2}{*}{ Outcome } & \multirow[b]{2}{*}{ Setting } & \multicolumn{2}{|l|}{ Men } & \multicolumn{2}{|l|}{ Women } \\
\hline & & $\begin{array}{l}\text { Cases/at-risk } \\
\text { sample }\end{array}$ & $\begin{array}{l}\text { Incidence rate } \\
(95 \% \mathrm{Cl})\end{array}$ & $\begin{array}{l}\text { Cases/at-risk } \\
\text { sample }\end{array}$ & $\begin{array}{l}\text { Incidence rate } \\
(95 \% \mathrm{Cl})\end{array}$ \\
\hline \multirow[t]{3}{*}{ Overweight/obesity* } & Vellore - rural & $70 / 223$ & 2.3 (1.9 to 2.8 ) & $89 / 197$ & 3.3 (2.8 to 3.9 ) \\
\hline & Vellore - urban & $90 / 224$ & 3.0 (2.5 to 3.4$)$ & $88 / 154$ & 4.2 (3.6 to 4.8 ) \\
\hline & New Delhi - urban & $119 / 339$ & 5.1 (4.4 to 5.9$)$ & $92 / 239$ & $5.6(4.7$ to 6.5$)$ \\
\hline \multirow[t]{3}{*}{ Obesity* } & Vellore - rural & $11 / 237$ & 0.3 (0.2 to 0.6$)$ & $33 / 216$ & 1.1 (0.8 to 1.5$)$ \\
\hline & Vellore - urban & $32 / 271$ & 0.9 (0.6 to 1.2$)$ & $60 / 208$ & 2.1 (1.7 to 2.6 ) \\
\hline & New Delhi - urban & $82 / 589$ & 2.0 (1.6 to 2.5$)$ & $60 / 386$ & 2.3 (1.8 to 2.8 ) \\
\hline \multirow[t]{3}{*}{ Central obesity } & Vellore - rural & $85 / 219$ & $2.9(2.4$ to 3.4$)$ & $90 / 187$ & 3.5 (3.0 to 4.1$)$ \\
\hline & Vellore - urban & $116 / 221$ & 3.9 (3.4 to 4.4$)$ & $96 / 147$ & 4.8 (4.2 to 5.4$)$ \\
\hline & New Delhi - urban & $143 / 316$ & $6.6(5.7$ to 7.4$)$ & $115 / 231$ & 7.2 (6.3 to 8.2 ) \\
\hline \multirow[t]{3}{*}{ Type 2 diabetes } & Vellore - rural & $42 / 236$ & 1.3 (1.0 to 1.7$)$ & $24 / 213$ & 0.8 (0.5 to 1.2$)$ \\
\hline & Vellore - urban & $41 / 268$ & $1.1(0.8$ to 1.5$)$ & $34 / 218$ & 1.2 (0.8 to 1.6$)$ \\
\hline & New Delhi - urban & $43 / 596$ & $1.0(0.8$ to 1.4$)$ & $15 / 413$ & 0.5 (0.3 to 0.9$)$ \\
\hline \multirow[t]{3}{*}{ Hypertension† } & Vellore - rural & $55 / 236$ & 1.7 (1.3 to 2.1$)$ & $23 / 216$ & 0.8 (0.5 to 1.1$)$ \\
\hline & Vellore - Urban & $67 / 263$ & 1.9 (1.5 to 2.3$)$ & $28 / 223$ & 0.9 (0.6 to 1.3$)$ \\
\hline & New Delhi - Urban & $168 / 575$ & 4.2 (3.7 to 4.8$)$ & $52 / 420$ & 1.8 (1.4 to 2.3 ) \\
\hline \multirow[t]{3}{*}{ Hypertriglyceridemiał } & Vellore - Rural & $68 / 200$ & 2.5 (2.0 to 3.0$)$ & $29 / 203$ & $1.1(0.7$ to 1.4$)$ \\
\hline & Vellore - Urban & $70 / 207$ & 2.5 (2.0 to 3.0$)$ & $25 / 202$ & 0.9 (0.7 to 1.3$)$ \\
\hline & New Delhi - Urban & $102 / 368$ & 4.0 (3.4 to 4.7$)$ & $61 / 382$ & 2.3 (1.8 to 2.9 ) \\
\hline \multirow[t]{3}{*}{ Hypercholesterolemiał } & Vellore - Rural & $34 / 230$ & $1.2(0.7$ to 1.5$)$ & $14 / 208$ & 0.5 (0.3 to 0.8$)$ \\
\hline & Vellore - Urban & $50 / 235$ & 1.5 (1.2 to 1.9$)$ & 24/197 & 0.9 (0.6 to 1.3$)$ \\
\hline & New Delhi - Urban & $123 / 350$ & 5.1 (4.4 to 5.9$)$ & $80 / 298$ & 3.9 (3.2 to 4.7$)$ \\
\hline \multirow[t]{3}{*}{ Low HDL-cholesterol } & Vellore - Rural & $23 / 82$ & 2.0 (1.3 to 2.8$)$ & $23 / 39$ & 4.2 (3.0 to 5.4$)$ \\
\hline & Vellore - Urban & $37 / 108$ & 2.5 (1.8 to 3.2$)$ & $18 / 45$ & 2.9 (1.8 to 4.0$)$ \\
\hline & New Delhi - Urban & $61 / 415$ & 2.1 (1.7 to 2.7$)$ & $56 / 205$ & 4.0 (3.1 to 4.9$)$ \\
\hline
\end{tabular}

${ }^{*} \mathrm{BMI}$ status at phase 5 for two study participants (rural men an urban men) and at phase 6 for one study participant (urban men). †Systolic and diastolic blood pressure values for two participants (one urban woman and one urban man) at phase 6 , $\ddagger$ Triglyceride and cholesterol levels at phase 6 for one urban man.

BMI, body mass index; CVD, cardiovascular disease; HDL, high-density lipoprotein.

and among urban men small differences in age, alcohol intake and PA. Urban women studied in phase 6 had a significantly higher BMI and WC in phase 5 and slightly higher fasting glucose, total and LDL-cholesterol concentrations than those not studied.

\section{DISCUSSION}

Our results show, in the VBC, that: (i) there was a high prevalence of CVD risk factors at age 28 years and a marked increase in prevalence by age 42 years; (2) the prevalence was higher in urban than rural participants at both time points; however, the incidence was similar in both groups and, for diabetes and hypertension, it was higher among rural residents; (3) compared with other countries, the prevalence of diabetes and hypertension in Vellore was higher than expected relative to obesity rankings; (4) higher 28-year WC was independent predictor of incident T2D, hypertension and hypertriglyceridemia.

\section{High prevalence of CVD risk factors at a young age and low BMI}

Asian Indians develop hypertension, T2D, and CVD at a younger age compared with other ethnic groups. ${ }^{1314}$ Similarly, a high prevalence of these CVD risk factors at relatively low levels of BMI has been recognized for several decades. ${ }^{15}$ Reasons for this remain unclear and could reflect greater genetic/epigenetic susceptibility and/ or other causal factors. Genetic studies do not indicate a greater risk of T2D or hypertension in Asian Indians, as risk estimates of single nucleotide polymorphisms are similar to those in Caucasians. ${ }^{16}$ However, evidence to suggest a possible epigenetic mechanism, linked to $\beta$-cell dysfunction, is reported. ${ }^{17}$ Traditional lifestyle risk factors operate similarly across different populations and ethnic groups. ${ }^{18}$ The differences in prevalence estimates across different countries apparently exposed to similar lifestyle factors could be explained by early exposure to novel risk factor such as environmental pollutants, ${ }^{19}$ impaired 
Table 3 Phase 5 predictors of incident hypertension, type 2 diabetes and hypertriglyceridemia in phase 6

\begin{tabular}{|c|c|c|c|}
\hline & $\begin{array}{l}\text { Hypertension } \\
\text { OR }(95 \% \mathrm{Cl})\end{array}$ & $\begin{array}{l}\text { Type } 2 \text { diabetes } \\
\text { OR }(95 \% \mathrm{Cl})\end{array}$ & $\begin{array}{l}\text { Hypertriglyceridemia } \\
\text { OR }(95 \% \mathrm{Cl})\end{array}$ \\
\hline Gender (male 0/female 1) & $0.42(0.26 \text { to } 0.66)^{*}$ & 0.88 (0.55 to 1.40$)$ & $0.42(0.29 \text { to } 0.62)^{*}$ \\
\hline \multicolumn{4}{|l|}{ Place of residence } \\
\hline (Rural 0/urban 1) & $0.63(0.42$ to 0.96$) \ddagger$ & 0.59 (0.39 to 0.91$) \ddagger$ & 0.78 (0.56 to 1.09$)$ \\
\hline Age (years) & 1.05 (0.87 to 1.27$)$ & 1.06 (0.87 to 1.29$)$ & 0.97 (0.83 to 1.13 ) \\
\hline \multicolumn{4}{|l|}{ Phase 5 predictors } \\
\hline Waist circumference (z) & $1.29(1.07$ to 1.57$) \dagger$ & $2.13(1.73 \text { to } 2.62)^{*}$ & $1.52(1.30 \text { to } 1.79)^{*}$ \\
\hline Physical activity (logged, z) & 1.15 (0.96 to 1.38$)$ & 0.93 (0.77 to 1.12$)$ & $1.02(0.88$ to 1.18$)$ \\
\hline SES score $(z)$ & $1.36(1.09$ to 1.70$) \dagger$ & 1.03 (0.82 to 1.29$)$ & 1.10 (0.92 to 1.31$)$ \\
\hline Alcohol use $(0-3) \S$ & 1.21 (0.93 to 1.59$)$ & 0.96 (0.71 to 1.30$)$ & $1.31(1.05$ to 1.64$) \ddagger$ \\
\hline Tobacco use $(0-3) \S$ & 0.89 (0.64 to 1.23$)$ & 1.30 (0.92 to 1.84$)$ & 1.35 (1.04 to 1.74$) \ddagger$ \\
\hline Educational status (0-6)ף & 0.97 (0.85 to 1.11$)$ & 1.08 (0.94 to 1.24$)$ & 0.97 (0.87 to 1.08$)$ \\
\hline Family history (No/Yes) & 1.67 (1.09 to 2.56$) \ddagger$ & $1.13(0.70$ to 1.81$)$ & Data not available \\
\hline
\end{tabular}

Model adjusted for Phase-5 predictors, age, sex, place of residence (rural/urban).

${ }^{*} P$ value $<0.001$.

$\dagger P$ value $<0.01$

$\ddagger P$ value $<0.05$.

$\S$ Alcohol use and tobacco use categorized as four levels from none to heavy.

१Educational status categorized as seven levels from illiterate to professional grade.

CVD, cardiovascular disease; SES, socioeconomic status.

early growth resulting from fetal and infant early/under nutrition operating at different stages of the life course and the 'thin-fat' body composition, inherent of Asian Indians, characterized by a low lean body mass and a high fat mass distributed more centrally. ${ }^{21}$

\section{Rural versus urban disease frequency}

The rise in CVD risk factors in rural populations (hitherto considered 'protected' by lower energy intakes and a higher physical workload) has important public health implications, because $70 \%$ of India's population is rural, with poor access to healthcare. Recent studies from India and other LMICs have shown a shift in CVD risk burden from urban towards rural areas, probably linked to recent rapid economic development, accompanied by dietary and lifestyle transitions, in rural India. ${ }^{22}{ }^{23}$ We found a similar increase in the prevalence of all risk factors in the rural and urban populations. The incidence of risk factors in the rural group was comparable with urban rates, and for T2D and hypertension, it was higher (table 2). We speculate that the rural population is more sensitive to low adiposity thresholds and other aspects of transition and warrants further investigation.

\section{Comparison of incidence rates}

Incidence data in India are currently limited to three urban studies covering hypertension, ${ }^{24} \mathrm{~T} 2 \mathrm{D},{ }^{25}$ and multiple risk factors, ${ }^{11}$ and our results, especially the rural data, are an important addition to the literature. The Cardio-metabolic Risk Reduction in South Asia (CARRS) study of 16000 men and women aged 20-60 years in Delhi and Chennai found an age-adjusted hypertension incidence over 2 years (2010-2012) of 4.7 and
3.6 per 100 per annum, respectively. ${ }^{24}$ The Chennai Rural Urban Epidemiology Study (CURES) study of 2410 men and women aged $\sim 50$ years in urban Chennai followed over 9 years (2001-2003 to 2012-2013) showed a diabetes incidence of 2.2 per 100 per annum. ${ }^{25}$ The NDBC studied 1100 men and women, comparable in age to the Vellore cohort, over 6.9 years (1998-2002 to 20062009) (table 2). Collectively, these studies suggest that the incidence is even higher in large cities than in either rural or urban Vellore possibly related to the differences in the distribution of the specific risk factors in different settings. The differing patterns of disease risk within a country can have important implications in implementing successful measures towards CVD prevention. Non-availability of comparable time-specific incidence data from HICs limits global incidence comparisons.

\section{Predictors of incident CVD risk factors}

Our finding that WC is a strong predictor of incident risk factors is consistent with the known correlations between WC and a range of metabolic abnormalities, including reduced insulin sensitivity and dyslipidemia. ${ }^{26}$ Nearly half our cohort participants were centrally obese in phase 6 , and central obesity showed the greatest increase with age/time of all the adiposity measures (table 2). It has been estimated that $15 \%$ and $36 \%$ of CVD-related and diabetes-related disability-adjusted life-years are attributable to high BMI or central adiposity in Indians. ${ }^{7}$ Biological determinants of CVD risk factors in LMICs are likely to be similar to those of developed countries ${ }^{19}$ but the drivers of these determinants are likely to differ. Greater SES at baseline predicted incident hypertension, in line 
with our previous observation of greater levels of CVD risk factors in higher SES groups. ${ }^{27}$ Contrastingly, some recent observations from India have shown higher CVD risk in lower SES strata. ${ }^{28}$ Thus, India may be showing the same systematic shift in CVD risk as that seen in HICs, where CVD appeared first in more affluent social groups and over a period of 50 years became more prominent in deprived social groups. ${ }^{29}$

\section{Strengths and limitations of the study}

Strengths of our study are its prospective design, following the same individuals with the same comprehensive set of measurements at both time points, the use of an OGTT to ascertain diabetes, and contemporaneous rural-urban and global comparisons. The longitudinal nature of the study on same set of non-migrant individuals is first of the kind to provide information on the CVD burden with passage of time. The incidence data are a valuable contribution to currently scarce national and global data from rural populations, and our study was well designed to examine rural-urban differences. A limitation was the narrow age range (42-45 years) of participants, which made it impossible to determine how much of the increased prevalence was due to age and how much to secular trends. There was evidence of possible selection bias among urban women; those who participated in phase 6 had greater adiposity in phase 5 than non-participants. Incidence estimates may therefore have been exaggerated in that group.

\section{CONCLUSION AND POLICY IMPLICATIONS}

Our study highlights a high prevalence of CVD risk factors at a young age in India compared with HIC and UMICs and rapid recent increments that are comparable or even greater, particularly in the rural population. Adiposity is an important driver of this increase, but the prevalence of hypertension and T2D is higher than expected given relatively low obesity rates in global terms, suggesting greater sensitivity to adiposity and/or other unmeasured causal factors, among Indians. CVD risk prevention is one of the important priorities among the nation's sustainable development goals. Public health strategies aimed at younger age groups and rural populations would curtail the increasing burden CVD burden in India and globally. Results from this study will guide preventive strategies and support policy making.

\author{
Author affiliations \\ ${ }^{1} 0 x f o r d$ Centre for Diabetes, Endocrinology and Metabolism, University of 0xford, \\ Oxford, UK \\ ${ }^{2}$ MRC Lifecourse Epidemiology Unit, University of Southampton, Southampton, UK \\ ${ }^{3}$ Department of Biostatistics, Christian Medical College and Hospital Vellore, Vellore, \\ Tamil Nadu, India \\ ${ }^{4}$ Department of Clinical Biochemistry, Christian Medical College and Hospital \\ Vellore, Vellore, Tamil Nadu, India \\ ${ }^{5}$ Department of Endocrinology, Diabetes and Metabolism, Christian Medical College \\ and Hospital Vellore, Vellore, Tamil Nadu, India
}

Acknowledgements We would like to thank the participants and the Vellore Birth Cohort field team for data collection. We are thankful to Professor Santosh
Bhargava and Professor HPS Sachdev for sharing New Delhi Birth Cohort data. We would like to thank the Non-Communicable Disease Risk Collaboration collaborators for sharing the global age-specific and year-specific prevalence data.

Contributors SKV, BA and CHDF initiated the study. All authors contributed to data collection, pooling analysis, and preparation of the results. SKV, BA, MG, MJ, CO and CHDF had full access to all of the data in the study and take responsibility for the integrity of the data and the accuracy of the data analysis. MG, BA, CO and HYS were involved in the acquisition, analysis, or interpretation of data. SKV and CHDF wrote the first draft of the manuscript. All other authors commented on the paper and contributed to the revision. SKV had full access to all the data in the study and had final responsibility for the decision to submit for publication. The corresponding author attests that all listed authors meet authorship criteria and that no others meeting the criteria have been omitted.

Funding Phase 5 follow-up of the study was supported by funds from the British Heart Foundation, UK (BHF_RG/98001 and BHF_CS/15/4/31493). Phase 6 follow-up was supported jointly by the London School of Hygiene \& Tropical Medicine, Indian Institute of Public Health, Hyderabad (WTP Project grant/09-2012) and internal funds from Christian Medical College, Vellore. SKV is funded by British Heart Foundation Clinical Research grant, no. CRM: 0022324.

Disclaimer The sponsors did not play a significant role in the analysis, interpretation or presentation of the results.

Competing interests None declared.

Patient consent for publication Not required.

Ethics approval This study was approved by the institutional review board - ethics committee of Christian Medical College, Vellore (IRB Min No: 9548 OBSERV).

Provenance and peer review Not commissioned; externally peer reviewed.

Data availability statement Data are available on reasonable request from the corresponding author

Supplemental material This content has been supplied by the author(s). It has not been vetted by BMJ Publishing Group Limited (BMJ) and may not have been peer-reviewed. Any opinions or recommendations discussed are solely those of the author(s) and are not endorsed by BMJ. BMJ disclaims all liability and responsibility arising from any reliance placed on the content. Where the content includes any translated material, BMJ does not warrant the accuracy and reliability of the translations (including but not limited to local regulations, clinical guidelines, terminology, drug names and drug dosages), and is not responsible for any error and/or omissions arising from translation and adaptation or otherwise.

Open access This is an open access article distributed in accordance with the Creative Commons Attribution 4.0 Unported (CC BY 4.0) license, which permits others to copy, redistribute, remix, transform and build upon this work for any purpose, provided the original work is properly cited, a link to the licence is given, and indication of whether changes were made. See: https://creativecommons.org/ licenses/by/4.0/.

\section{ORCID iDs}

Senthil K Vasan http://orcid.org/0000-0002-3630-6568

Fredrik Karpe http://orcid.org/0000-0002-2751-1770

Matthew Johnson http://orcid.org/0000-0001-5597-6615

\section{REFERENCES}

1 Harikrishnan S, Leeder S, Huffman A, et al. A race against time: the challenge of cardiovascular diseases in developing economies. centre for chronic disease control. New Delhi, India, 2014.

2 Institute for Health Metrics and Evaluation (IHME). GBD compare data visualization. Seattle, WA: IHME UoW, 2017. http://vizhub. healthdata.org/gbdcompare

3 India State-Level Disease Burden Initiative Collaborators. Nations within a nation: variations in epidemiological transition across the states of India, 1990-2016 in the global burden of disease study. Lancet 2017;390:2437-60.

4 Anjana RM, Deepa M, Pradeepa R, et al. Prevalence of diabetes and prediabetes in 15 states of India: results from the ICMR-INDIAB population-based cross-sectional study. Lancet Diabetes Endocrinol 2017;5:585-96.

5 Joshi SR, Anjana RM, Deepa M, et al. Prevalence of dyslipidemia in urban and rural India: the ICMR-INDIAB study. PLoS One 2014;9:e96808.

6 Geldsetzer P, Manne-Goehler J, Theilmann M, et al. Diabetes and hypertension in India: a nationally representative study of 1.3 million adults. JAMA Intern Med 2018;178:363-72. 
7 India State-Level disease burden initiative CVDC. The changing patterns of cardiovascular diseases and their risk factors in the states of India: the global burden of disease study 1990-2016. Lancet Glob Health 2018;6:e1339-51.

8 Antonisamy B, Raghupathy P, Christopher S, et al. Cohort profile: the 1969-73 Vellore birth cohort study in South India. Int J Epidemiol 2009;38:663-9.

9 NCD Risk Factor Collaboration (NCD-RisC). Worldwide trends in diabetes since 1980: a pooled analysis of 751 population-based studies with 4.4 million participants. Lancet 2016;387:1513-30.

10 NCD Risk Factor Collaboration (NCD-RisC). Worldwide trends in blood pressure from 1975 to 2015: a pooled analysis of 1479 population-based measurement studies with $19 \cdot 1$ million participants. Lancet 2017;389:37-55.

11 Huffman MD, Prabhakaran D, Osmond C, et al. Incidence of cardiovascular risk factors in an Indian urban cohort results from the new Delhi birth cohort. J Am Coll Cardiol 2011;57:1765-74.

12 Vasan SK, Roy A, Samuel VT, et al. IndEcho study: cohor study investigating birth size, childhood growth and young adult cardiovascular risk factors as predictors of midlife myocardial structure and function in South Asians. BMJ Open 2018;8:e019675.

13 Gujral UP, Mohan V, Pradeepa R, et al. Ethnic differences in the prevalence of diabetes in underweight and normal weigh individuals: the CARRS and NHANES studies. Diabetes Res Clin Pract 2018;146:34-40.

14 Joshi P, Islam S, Pais P, et al. Risk factors for early myocardial infarction in South Asians compared with individuals in other countries. JAMA 2007;297:286-94.

15 Deurenberg-Yap M, Chew SK, Deurenberg P. Elevated body fat percentage and cardiovascular risks at low body mass index levels among Singaporean Chinese, Malays and Indians. Obes Rev 2002;3:209-15.

16 Sohani ZN, Deng WQ, Pare G, et al. Does genetic heterogeneity account for the divergent risk of type 2 diabetes in South Asian and white European populations? Diabetologia 2014;57:2270-81.

17 Chambers JC, Loh M, Lehne B, et al. Epigenome-Wide association of DNA methylation markers in peripheral blood from Indian Asians and Europeans with incident type 2 diabetes: a nested case-control study. Lancet Diabetes Endocrinol 2015;3:526-34.
18 Yusuf S, Hawken S, Ounpuu S, et al. Effect of potentially modifiable risk factors associated with myocardial infarction in 52 countries (the INTERHEART study): case-control study. Lancet 2004;364:937-52.

19 India State-Level Disease Burden Initiative Air Pollution Collaborators. The impact of air pollution on deaths, disease burden, and life expectancy across the states of India: the global burden of disease study 2017. Lancet Planet Health 2019;3:e26-39.

20 NCD Risk Factor Collaboration (NCD-RisC). Trends in adult bodymass index in 200 countries from 1975 to 2014: a pooled analysis of 1698 population-based measurement studies with $19 \cdot 2$ million participants. Lancet 2016;387:1377-96.

21 Yajnik CS, Fall CHD, Coyaji KJ, et al. Neonatal anthropometry: the thin-fat Indian baby. The Pune maternal nutrition study. Int $J$ Obes Relat Metab Disord 2003;27:173-80.

22 Hwang CK, Han PV, Zabetian A, et al. Rural diabetes prevalence quintuples over twenty-five years in low- and middle-income countries: a systematic review and meta-analysis. Diabetes Res Clin Pract 2012;96:271-85.

23 Prabhakaran D, Roy A, Praveen PA, et al. 20-Year trend of CVD risk factors: urban and rural national capital region of India. Glob Heart 2017;12:209-17.

24 Prabhakaran D, Jeemon P, Ghosh S, et al. Prevalence and incidence of hypertension: results from a representative cohort of over 16,000 adults in three cities of South Asia. Indian Heart J 2017;69:434-41.

25 Anjana RM, Shanthi Rani CS, Deepa M, et al. Incidence of diabetes and prediabetes and predictors of progression among Asian Indians: 10-year follow-up of the Chennai urban rural epidemiology study (cures). Diabetes Care 2015;38:1441-8.

26 Huxley R, Mendis S, Zheleznyakov E, et al. Body mass index, waist circumference and waist:hip ratio as predictors of cardiovascular risk--a review of the literature. Eur J Clin Nutr 2010;64:16-22.

27 Samuel P, Antonisamy B, Raghupathy P, et al. Socio-Economic status and cardiovascular risk factors in rural and urban areas of Vellore, Tamilnadu, South India. Int J Epidemiol 2012;41:1315-27.

28 Gupta R, Deedwania PC, Sharma K, et al. Association of educational, occupational and socioeconomic status with cardiovascular risk factors in Asian Indians: a cross-sectional study. PLoS One 2012;7:e44098.

29 Barker DJ. Rise and fall of Western diseases. Nature 1989;338:371-2. 